\title{
An des Walensees Gestade
}

An des Walensees Gestade

Drängts nicht mehr zum Bade

Gemächlich fährt das Schiff dahin

Mit hüpft auch der Frohsinn.

Winkt dem Sommer Ade

Versteckt ein Ach und Weh

Blätter fallen schon

Nach dem roten Mohn

Stille bleibt zurück

Schönheit entzückt

Sei golden Herbst

So mein Gemüt du stärkst

Noch fliesst der Wein

Noch besitz ich mein Heim

Doch einmal kommt die Wende

Bildnachweis

Alles hat sein Ende.

Dr. med. Hedi Meierhans

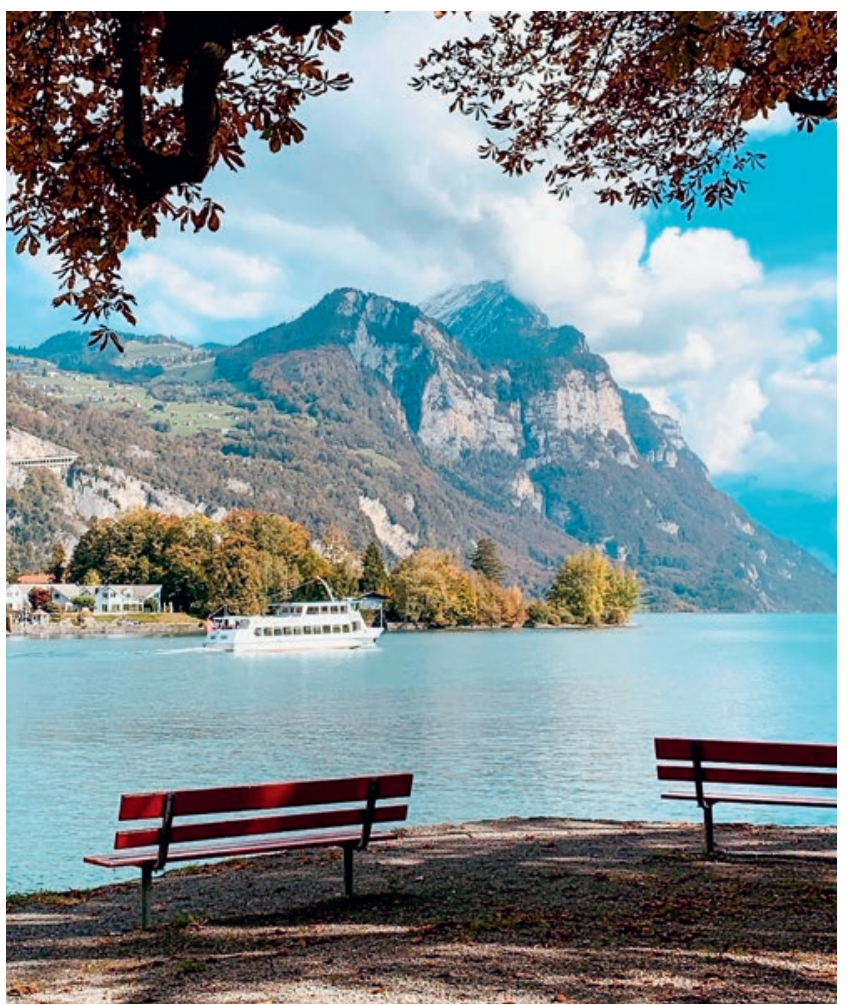

he.meierhans[at]bluewin.ch

\section{Abschiednehmen}

Jeden Tag

beginnt das Abschiednehmen aber es endet nie

und dennoch beginnt es immer wieder!

Dr. med. Harriet Keller-Wossidlo

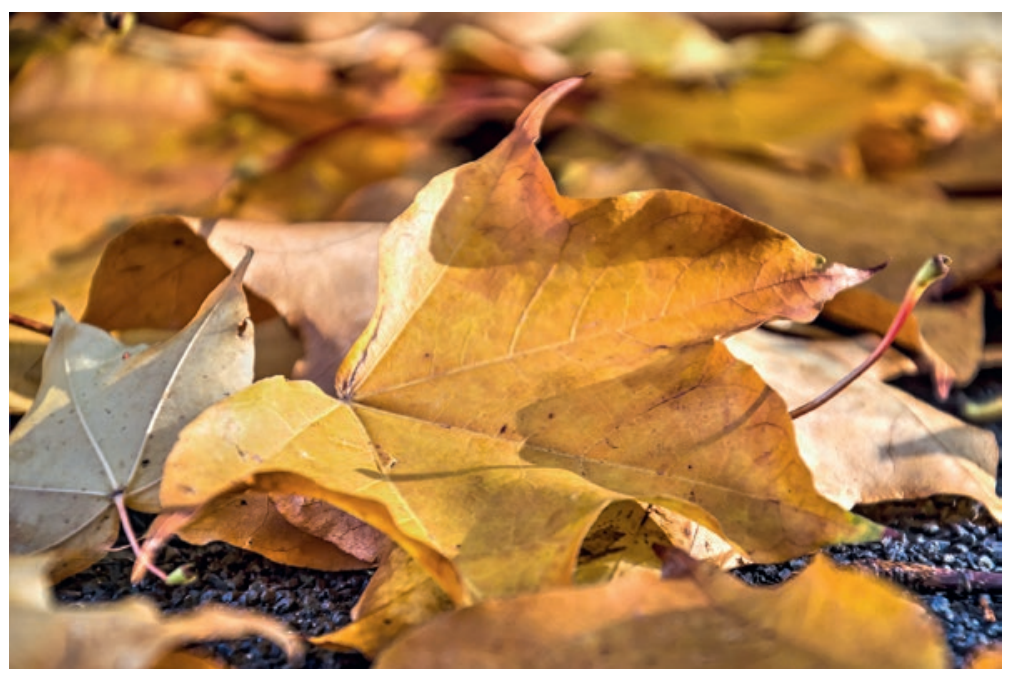

EMHMedia 